\title{
Optimization of 6061T6 CNC Boring Process Using the Taguchi Method and Grey Relational Analysis
}

\author{
Show-Shyan Lin, Ming-Tsan Chuang, Jeong-Lian Wen, and Yung-Kuang Yang* \\ Department of Mechanical Engineering, Minghsin University of Science and Technology, Taiwan
}

\begin{abstract}
This study investigated the optimization of computer numerical control (CNC) boring operation parameters for aluminum alloy 6061T6 using the grey relational analysis (GRA) method. Nine experimental runs based on an orthogonal array of Taguchi method were performed. The surface properties of roughness average and roughness maximum as well as the roundness were selected as the quality targets. An optimal parameter combination of the CNC boring operation was obtained via GRA. By analyzing the grey relational grade matrix, the degree of influenced for each controllable process factor onto individual quality targets can be found. The feed rate is identified to be the most influence on the roughness average and roughness maximum, and the cutting speed is the most influential factor to the roundness. Additionally, the analysis of variance (ANOVA) was also applied to identify the most significant factor; the feed rate is the most significant controlled factor for the $\mathrm{CNC}$ boring operations according to the weighted sum grade of the roughness average, roughness maximum and roundness.
\end{abstract}

\section{INTRODUCTION}

Boring is a precision machining process for generating internal cylindrical forms by removing metal with singlepoint tools or tools with multiple cutting edges. This process is most commonly performed with the workpiece held stationary and the cutting tool both rotating and advancing into the work. Common applications for boring include the enlarging or finishing of cored, pierced, or drilled holes and contoured internal surfaces. Related operations sometimes performed simultaneously with boring include turning, facing, chamfering, grooving, and threading. Precision boring can be performed on machines specifically designed for this purpose. In general, these machines relatively use light cuts, maintain close tolerances, and are often capable of high production rates. Additionally, machining centers (MC) have been defined as CNC machines with automatic tool-changing capabilities and rotating cutting tools. Increased productivity and versatility are major advantages of MC.

The ability to perform drilling, turning, reaming, boring, milling, contouring, and threading operations on single machine eliminates the need for a number of individual machine tools, thus reducing capital equipment and labor requirements. Therefore, aluminum alloy $6061 \mathrm{~T} 6$ boring process is done on the various cutting parameters of MC and is discussed in this study. The current boring operation can increase productivity if compared with a grinding operation. The boring process parameters such as cutting tool geometry and materials, depth of cut, feed rates, cutting speeds impact the material removal rates and the machining quality such as surface roughness and roundness has been studied intensively.

*Address correspondence to this author at the Minghsin University of Science and Technology, 1, Hsin Hsing Road, Hsin Feng, 304 , Hsinchu, Taiwan; Tel: +886-3-5593142 ext.3001; Fax: +886-3-5782822, E-mail: yky@must.edu.tw
Recently, Deng (1989) [1] proposed a grey relational analysis (GRA). The GRA is a method for measuring the degree of approximation among the sequences using a grey relational grade. Theories of the GRA have attracted considerable interest among researchers. Some other researchers have also examined the optimization of process parameters. For example, Huang and Lin (2002) [2] applied the GRA to design the die-sinking EDM machining parameters. Fung et al. (2003) [3] studied the GRA to obtain the optimal parameters of the injection molding process for mechanical properties of yield stress and elongation in polycarbonate/acrylonitrile-butadiene-styrene (PC/ABS) composites. Shen et al. (2004) [4] studied different polymers (such as PP, PC, PS, POM) with various process parameters of the micro-gear. The simulation used Taguchi method and GRA was provided. An employed the Taguchi method and the GRA to optimize the turning operations with multiple performance characteristics by Lin (2004) [5]. A used the GRA to optimize of the wire electric discharge machining process of particle-reinforced material with multiple performance characteristics by Chiang and Chang (2006) [6]. Yang et al. (2006) [7] also applied the Taguchi method and the GRA to optimize the dry machining parameters for high-purity graphite in end milling process, etc.

Planning the experiments through the Taguchi orthogonal array has been used quite successfully in process optimization by Chen and Chen (2007) [8], Fung and Kang (2005) [9], Tang et al. (2007) [10], Vijian and Arunachalam (2006) [11], Yang (2007) [12] as well as Zhang et al. (2007) [13], etc. Therefore, this study applied a Taguchi $\mathrm{L}_{9}\left(3^{4}\right)$ orthogonal array to plan the experiments on CNC boring operations. Three controlling factors including the cutting speed, the feed rate, and the depth of cut with three levels for each factor were selected. The GRA is then applied to examine how the $\mathrm{CNC}$ boring operation factors influence the quality targets of roughness average, roughness maximum and roundness. An optimal parameter combination was then 
obtained. Through analyzing the grey relational grade matrix, the most influential factors for individual quality targets of the CNC boring operations can be identified. Additionally, the ANOVA was also utilized to examine the most significant factors for the $\mathrm{CNC}$ boring process as the roughness average, roughness maximum and roundness are simultaneously considered.

\section{GREY RELATIONAL ANALYSIS}

\section{Data Preprocessing}

Grey data processing must be performed before grey correlation coefficients can be calculated. A series of various units must be transformed to be dimensionless. Usually, each series is normalized by dividing the data in the original series by their average.

Let the original reference sequence and sequence for comparison be represented as $x_{0}(k)$ and $x_{i}(k), i=1,2, \ldots, m$; $k=1,2, \ldots, n$, respectively, where $m$ is the total number of experiment to be considered, and $n$ is the total number of observation data. Data preprocessing converts the original sequence to a comparable sequence. Several methodologies of preprocessing data can be used in grey relation analysis, depending on the characteristics of the original sequence (Deng, 1989 [1]; Gau et al., 2006 [14]; You et al., 2007 [15]). If the target value of the original sequence is "the-larger-the-better', then the original sequence is normalized as follows,

$$
x_{i}^{*}(k)=\frac{x_{i}^{(0)}(k)-\min \cdot x_{i}^{(0)}(k)}{\max \cdot x_{i}^{(0)}(k)-\min \cdot x_{i}^{(0)}(k)}
$$

If the purpose is "the-smaller-the-better", then the original sequence is normalized as follows,

$$
x_{i}^{*}(k)=\frac{\max \cdot x_{i}^{(0)}(k)-x_{i}^{(0)}(k)}{\max \cdot x_{i}^{(0)}(k)-\min \cdot x_{i}^{(0)}(k)}
$$

However, if there is "a specific target value", then the original sequence is normalized using,

$$
x_{i}^{*}(k)=1-\frac{\left|x_{i}^{(0)}(k)-O B\right|}{\max .\left\{\max . x_{i}^{(o)}(k)-O B, O B-\min . x_{i}^{(0)}(k)\right\}}
$$

where $O B$ is the target value.

Alternatively, the original sequence can be normalized using the simplest methodology that is the values of the original sequence can be divided by the first value of the sequence, $x_{i}^{(0)}(1)$.

$$
x_{i}^{*}(k)=\frac{x_{i}^{(o)}(k)}{x_{i}^{(O)}(1)}
$$

where

$$
\begin{aligned}
& x_{i}^{(o)}(k): \text { the original sequence } \\
& x_{i}^{*}(k) \text { : the sequence after the data preprocessing } \\
& \max . x_{i}^{(o)}(k) \text { : the largest value of } x_{i}^{(o)}(k)
\end{aligned}
$$

$$
\min . x_{i}^{(0)}(k) \text { : the smallest value of } x_{i}^{(o)}(k)
$$

\section{Grey Relational Coefficients and Grey Relational Grades}

Following the data preprocessing, a grey relational coefficient can be calculated using the preprocessed sequences. The grey relational coefficient is defined as follows.

$$
\begin{aligned}
& \gamma\left(x_{o}^{*}(k), x_{i}^{*}(k)\right)=\frac{\Delta_{\min .}+\zeta \Delta_{\max .}}{\Delta_{O i}(k)+\zeta \Delta_{\max } .} \\
& 0<\gamma\left(x_{o}^{*}(k), x_{i}^{*}(k)\right) \leq 1
\end{aligned}
$$

where

$\Delta_{O i}(k)$ is the deviation sequence of reference sequence $x_{o}^{*}(k)$ and comparability sequence $x_{i}^{*}(k)$, namely

$$
\begin{aligned}
& \Delta_{o i}(k)=\left|x_{O}^{*}(k)-x_{i}^{*}(k)\right| \\
& \Delta_{\text {max. }}=\underset{\forall j \in i \quad \forall k}{\max . \max }\left|x_{0}^{*}(k)-x_{j}^{*}(k)\right| \\
& \Delta_{\text {min. }}=\underset{\forall j \in i \forall k}{\min . \min } \cdot\left|x_{0}^{*}(k)-x_{j}^{*}(k)\right| \\
& \zeta \text { : distinguishing coefficient, } \zeta \in[0,1]
\end{aligned}
$$

A grey relational grade is a weighted sum of the grey relational coefficients, and is defined as follows.

$$
\begin{aligned}
& \gamma\left(x_{O}^{*}, x_{i}^{*}\right)=\sum_{k=1}^{n} \beta_{k} \gamma\left(x_{O}^{*}(k), x_{i}^{*}(k)\right) \\
& \sum_{k=1}^{n} \beta_{k}=1
\end{aligned}
$$

Here, the grey relational grade $\gamma\left(x_{0}^{*}, x_{i}^{*}\right)$ represents the level of correlation between the reference and comparability sequences. If the two sequences are identical, then the value of the grey relational grade equals to one. The grey relational grade also indicates the degree of influence exerted by the comparability sequence on the reference sequence. Consequently, if a particular comparability sequence is more important to the reference sequence than other comparability sequences, the grey relational grade for that comparability sequence and the reference sequence will exceed that for other grey relational grades. The GRA is actually a measurement of the absolute value of data difference between the sequences, and can be used to approximate the correlation between the sequences.

\section{EXPERIMENTAL PROCEDURES AND TEST RE- SULTS}

\section{Material}

Aluminum alloy $6061 \mathrm{~T} 6$ is one of the most widely used alloys in the 6000 Series. This standard structural alloy, one of the most versatile of the heat-treatable alloys, is popular for medium to high strength requirements and has good toughness characteristics. Applied range from transportation 
components to machinery and equipment applications to recreation products.

\section{Schematic of Machining}

Fig. (1) shows the machining setup of the boring process via a machining center. The experiments were carried out on a rigid computer numerical control (CNC) machine center with an $11 \mathrm{~kW}$ spindle motor at 8000rpm (machine type of VM-32S, manufactured by Fair Friend Group in Taiwan). At the same time, the boring cutting bar is manufactured by
Maho Enterprise Ltd., Taiwan, part number BJ1614-60, and the cutter tool is used number TPGH090204L. In this study, in order to properly control the depth of cut, first the internal diameter of the workpieces has been fixed to $14 \mathrm{~mm}$ via end milling cutting and the cutting depth of workpiece is $20 \mathrm{~mm}$. Furthermore, the cutting speed $(\mathrm{m} / \mathrm{min})$, the feed rate $(\mathrm{mm} / \mathrm{rev})$ and the depth of cut $(\mathrm{mm})$ can be regulated in this experiment of the CNC boring operations. Additionally, Fig. (2) also shows the range of surface roughness ( $\mathrm{Ra}$ ) to obtain in various processes [16].

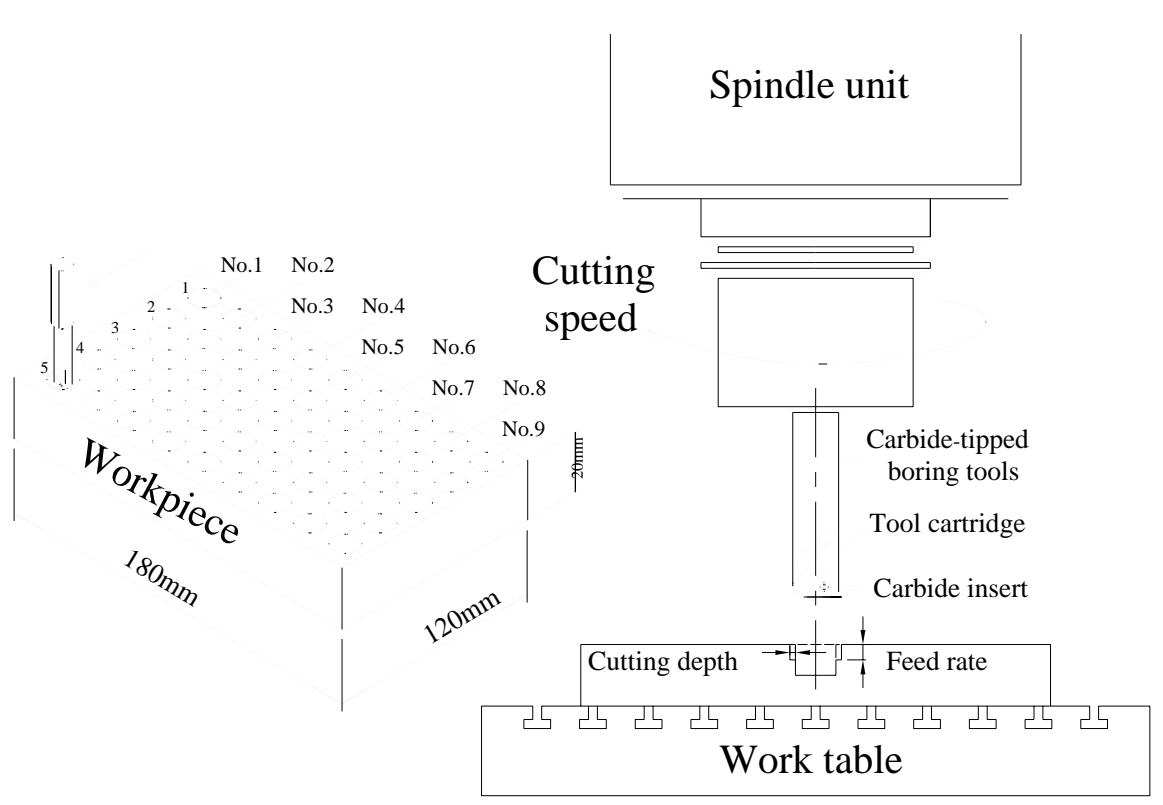

Fig. (1). Scheme of CNC boring operation.

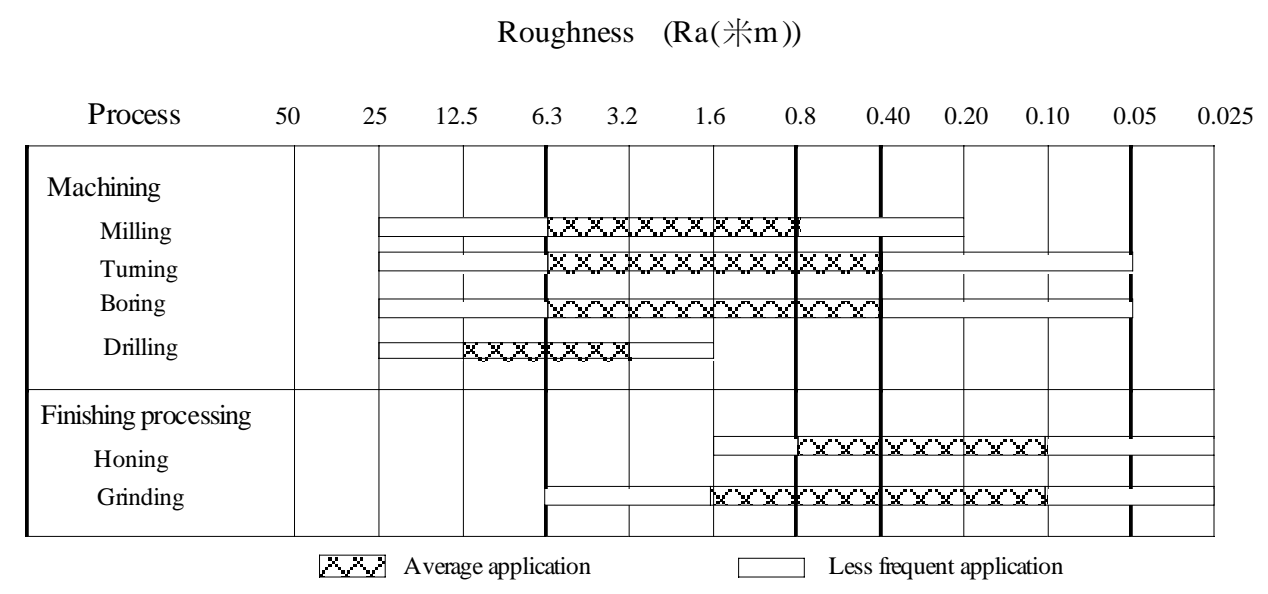

Fig. (2). The range of surface roughness (Ra) obtained in various processes.

\section{Experimental Parameters and Design}

The effects of CNC boring parameters on the surface roughness had been less discussion by research. Usually, the desired boring operation parameters can be determined from experience, a handbook or recommendation from the manufacturer. In this study, the experiment is conducted with three controllable 3-level factors and three response vari- ables. Nine experimental runs based on the orthogonal array $\mathrm{L}_{9}\left(3^{4}\right)$ are required. Table 1 presents three controlled factors of the cutting speed (i.e., A ( $\mathrm{m} / \mathrm{min})$ ), the feed rate (i.e., B $(\mathrm{mm} / \mathrm{rev}))$, and the depth of cut (i.e., C $(\mathrm{mm}))$ with three levels for each factor. Table 2 shows the nine cutting experimental runs according to the selected orthogonal table. After CNC boring operations, three quality objectives of the 
workpieces are chosen, including the roughness average (i.e., $\mathrm{Ra}(\mu \mathrm{m}))$, roughness maximum (i.e., Rt $(\mu \mathrm{m}))$ and roundness (i.e., $\psi(\mu \mathrm{m})$ ).

Table 1. Experimental Factors and Factor Levels

\begin{tabular}{|c|c|c|c|}
\hline \multirow{2}{*}{$\begin{array}{c}\text { Levels of Experi- } \\
\text { mental Factors }\end{array}$} & $\begin{array}{c}\text { A/ } \\
\text { Cutting Speed } \\
(\mathbf{m} / \mathbf{m i n})\end{array}$ & $\begin{array}{c}\text { B/ } \\
\text { Feed Rate } \\
(\mathbf{m m} / \mathbf{r e v})\end{array}$ & $\begin{array}{c}\text { C/ } \\
\text { Cut Depth } \\
(\mathbf{m m})\end{array}$ \\
\hline \hline 1 & 70 & 0.05 & 0.4 \\
\hline 2 & 85 & 0.10 & 0.5 \\
\hline 3 & 100 & 0.15 & 0.6 \\
\hline
\end{tabular}

\section{Measuring Apparatus}

The roughness average ( $\mathrm{Ra}$ ) and roughness maximum (Rt) of the surface after the CNC boring process were measured by a surface analyzer from

Form Talysurf 50 (Taylor Hobson Ltd., UK) and Form Talyrond 250 for the roundness $(\psi)$ of the circumference surface.

Table 2. Orthogonal Array $L_{9}\left(3^{4}\right)$ of the Experimental Runs and Results

\begin{tabular}{|c|c|c|c|c|c|c|}
\hline $\begin{array}{c}\text { Run } \\
\text { no. }\end{array}$ & A & B & C & $\operatorname{Ra}(\boldsymbol{\mu m})$ & $\operatorname{Rt}(\boldsymbol{\mu m})$ & $\boldsymbol{\psi}(\boldsymbol{\mu \mathbf { m } )}$ \\
\hline \hline 1 & 1 & 1 & 1 & 0.1362 & 1.1126 & 2.76 \\
\hline 2 & 1 & 2 & 2 & 0.5912 & 3.6129 & 2.32 \\
\hline 3 & 1 & 3 & 3 & 1.6178 & 8.3246 & 1.52 \\
\hline 4 & 2 & 1 & 3 & 0.1260 & 1.1460 & 0.68 \\
\hline 5 & 2 & 2 & 1 & 0.6376 & 5.2558 & 0.88 \\
\hline 6 & 2 & 3 & 2 & 1.7736 & 13.0625 & 1.36 \\
\hline 7 & 3 & 1 & 2 & 0.1605 & 2.1328 & 0.60 \\
\hline 8 & 3 & 2 & 3 & 0.6318 & 2.1968 & 1.68 \\
\hline 9 & 3 & 3 & 1 & 1.5866 & 8.1710 & 2.48 \\
\hline
\end{tabular}

\section{RESULTS AND DISCUSSION}

Table 2 shows the nine cutting experimental runs according to the $\mathrm{L}_{9}$ orthogonal table. Every experimental run by way of five $\mathrm{CNC}$ boring operations, three quality objectives of the fifth workpieces is measured, including the roughness average (i.e., $\mathrm{Ra}(\mu \mathrm{m}))$, roughness maximum (i.e., Rt $(\mu \mathrm{m}))$, and roundness (i.e., $\psi(\mu \mathrm{m})$ ).

\section{Best Experimental Run}

The experimental results for the $\mathrm{Ra}$, the $\mathrm{Rt}$ and the $\psi$ are listed in Table 2. Typically, smaller values of the Ra, the Rt and the $\psi$ are desirable. Thus, the data sequences have a the-smaller-the-better characteristic, the "smaller-the-better" methodology, i.e. Eq. (2), was employed for data preproc- essing. The values of the $\mathrm{Ra}$, the $\mathrm{Rt}$ and $\psi$ are set to be the reference sequence $x_{0}^{(0)}(k), k=1 \sim 3$. Moreover, the results of nine experiments were the comparability sequences $x_{i}^{(o)}(k), \quad i=1,2, \ldots, 9, \quad k=1 \sim 3$. Table 3 listed all of the sequences after implementing the data preprocessing using Eq. (2). The reference and the comparability sequences were denoted as $x_{o}^{*}(k)$ and $x_{i}^{*}(k)$, respectively. Also, the deviation sequences $\Delta_{0 i}, \Delta_{\max }(k)$ and $\Delta_{\min .}(k)$ for $i=1 \sim 9$, $k=1 \sim 3$ can be calculated.

Table 3. The Sequences After Data Preprocessing

\begin{tabular}{|c|c|c|c|c|}
\hline \multicolumn{2}{|c|}{$\begin{array}{c}\text { Reference/Comparability } \\
\text { Sequence }\end{array}$} & $\mathbf{R a}$ & Rt & $\psi$ \\
\hline \multicolumn{2}{|c|}{ Reference Sequence } & 1.000 & 1.000 & 1.000 \\
\hline \multirow{9}{*}{$\begin{array}{l}\text { Comparability } \\
\text { Sequences }\end{array}$} & No. 1 & 0.9938 & 1.0000 & 0.0000 \\
\hline & No. 2 & 0.7176 & 0.7908 & 0.2037 \\
\hline & No. 3 & 0.0946 & 0.3965 & 0.5741 \\
\hline & No. 4 & 1.0000 & 0.9972 & 0.9630 \\
\hline & No. 5 & 0.6895 & 0.6533 & 0.8704 \\
\hline & No. 6 & 0.0000 & 0.0000 & 0.6481 \\
\hline & No. 7 & 0.9791 & 0.9146 & 1.0000 \\
\hline & No. 8 & 0.6930 & 0.9093 & 0.5000 \\
\hline & No. 9 & 0.1135 & 0.4093 & 0.1296 \\
\hline
\end{tabular}

Table 4. The Calculated Grey Relational Coefficient and Grey Relational Grade for Nine Comparability Sequences

\begin{tabular}{|c|c|c|c|c|c|c|c|}
\hline \multirow{2}{*}{$\begin{array}{c}\text { Experimental } \\
\text { Run (Compa- } \\
\text { rability } \\
\text { Sequences) }\end{array}$} & \multicolumn{3}{|c|}{$\begin{array}{r}\text { Orthogonal } \\
\text { Array } L_{9}\left(3^{4}\right)\end{array}$} & \multicolumn{3}{|c|}{$\begin{array}{c}\text { Grey Relational } \\
\text { Coefficient }\end{array}$} & \multirow[t]{2}{*}{$\begin{array}{l}\text { Grey Rela- } \\
\text { tional Grade }\end{array}$} \\
\hline & $\mathbf{A}$ & B & C & $\mathbf{R a}$ & Rt & $\psi$ & \\
\hline 1 & 1 & 1 & 1 & 0.9878 & 1.0000 & 0.3333 & 0.7737 \\
\hline 2 & 1 & 2 & 2 & 0.6391 & 0.7050 & 0.3857 & 0.5766 \\
\hline 3 & 1 & 3 & 3 & 0.3558 & 0.4531 & 0.5400 & 0.4496 \\
\hline 4 & 2 & 1 & 3 & 1.0000 & 0.9944 & 0.9310 & 0.9752 \\
\hline 5 & 2 & 2 & 1 & 0.6169 & 0.5905 & 0.7941 & 0.6672 \\
\hline 6 & 2 & 3 & 2 & 0.3333 & 0.3333 & 0.5870 & 0.4179 \\
\hline 7 & 3 & 1 & 2 & 0.9598 & 0.8542 & 1.0000 & 0.9380 \\
\hline 8 & 3 & 2 & 3 & 0.6196 & 0.8464 & 0.5000 & 0.6553 \\
\hline 9 & 3 & 3 & 1 & 0.3606 & 0.4584 & 0.3649 & 0.3946 \\
\hline
\end{tabular}

The distinguishing coefficient $\zeta$ can be substituted for the grey relational coefficient in Eq. (5). If all the process parameters have equal weighting, $\xi$ is set to be 0.5 . Table 4 listed the grey relational coefficients and the grade for all nine comparability sequences. 
This investigation employs the response table of the Taguchi method to calculate the average grey relational grades for each factor level, as illustrated in Table 5. Since the grey relational grades represented the level of correlation between the reference and the comparability sequences, the larger grey relational grade means the comparability sequence exhibiting a stronger correlation with the reference sequence. Based on this study, one can select a combination of the levels that provide the largest average response. In Table 5, the combination of $\mathrm{A}_{2}, \mathrm{~B}_{1}$, and $\mathrm{C}_{3}$ shows the largest value of the grey relational grade for the factors $\mathrm{A}, \mathrm{B}$, and $\mathrm{C}$, respectively. Therefore, $\mathrm{A}_{2} \mathrm{~B}_{1} \mathrm{C}_{3}$ with a cutting speed of $85 \mathrm{~m} / \mathrm{min}$, a feed rate of $0.05 \mathrm{~mm} / \mathrm{rev}$, and depth of cut of 0.6 $\mathrm{mm}$ is the optimal parameter combination of the $\mathrm{CNC}$ boring operations.

Table 5. The Response Table for Grey Relational Grade

\begin{tabular}{|c|c|c|c|}
\hline \multirow{2}{*}{ Levels } & \multicolumn{3}{|c|}{ Factors } \\
\cline { 2 - 4 } & $\mathbf{A}$ & $\mathbf{B}$ & $\mathbf{C}$ \\
\hline \hline 1 & 0.6000 & 0.8956 & 0.6118 \\
\hline 2 & 0.6867 & 0.6330 & 0.6442 \\
\hline 3 & 0.6627 & 0.4207 & 0.6934 \\
\hline
\end{tabular}

\section{Most Influential Factor}

In this study, the GRA is applied to examine how the boring operation parameters influence the quality targets of workpieces. The values of the factor level in nine experimental runs are set to the comparability sequences for three controllable factors. Table 6 listed all of the sequences.

Table 6. The Sequences After Data Preprocessing for the Reference Sequences and Comparability Sequences

\begin{tabular}{|c|c|c|c|c|c|c|}
\hline \multirow{2}{*}{$\begin{array}{c}\text { Exp. } \\
\text { Run }\end{array}$} & \multicolumn{3}{|c|}{ Comparability Sequences } & \multicolumn{3}{|c|}{ Reference Sequences } \\
\cline { 2 - 7 } & A & B & C & Ra & Rt & $\Psi$ \\
\hline \hline 1 & 1.00 & 1.00 & 1.00 & 1.000 & 1.000 & 1.0000 \\
\hline 2 & 1.00 & 2.00 & 1.25 & 4.3407 & 3.2473 & 0.8406 \\
\hline 3 & 1.00 & 3.00 & 1.50 & 11.8781 & 7.48213 & 0.5507 \\
\hline 4 & 1.21 & 1.00 & 1.50 & 0.9251 & 1.0300 & 0.2464 \\
\hline 5 & 1.21 & 2.00 & 1.00 & 4.6814 & 4.7239 & 0.3188 \\
\hline 6 & 1.21 & 3.00 & 1.25 & 13.0220 & 11.7405 & 0.4928 \\
\hline 7 & 1.43 & 1.00 & 1.25 & 1.1784 & 1.9170 & 0.2174 \\
\hline 8 & 1.43 & 2.00 & 1.50 & 4.6389 & 1.9745 & 0.6087 \\
\hline 9 & 1.43 & 3.00 & 1.00 & 11.6491 & 7.3441 & 0.8986 \\
\hline
\end{tabular}

Data preprocessing was performed based on Eq. (4), and Table 6 listed the normalized results. Subsequently, the deviation sequences were calculated using the method mentioned above. The deviation sequences and the distinguishing coefficient then were substituted into Eq. (5) to obtain the grey relational coefficients. Additionally, the grey relational coefficients are averaged using an equal weighting to obtain the grey relational grade. Table 7 listed the grey relational coefficients and the grade of the $\mathrm{Ra}$ of the reference sequence and comparability sequences. Table $\mathbf{8}$ gives the grey relational coefficients and the grade of the Rt for the reference sequence and the comparability sequences. Similarly, Table 9 shows the grey relational coefficients and the grade of the $\psi$ for the reference sequence and the comparability sequences.

The grey relational grades in Tables 7, Tables 8 and 9 can be further arranged in a matrix form shown as follows:

$$
\begin{aligned}
\gamma & =\left[\begin{array}{lll}
\gamma(\boldsymbol{R} a, A) & \gamma(\boldsymbol{R} a, \boldsymbol{B}) & \gamma(\boldsymbol{R} a, \boldsymbol{C}) \\
\gamma\left(\boldsymbol{R}_{\boldsymbol{t}}, \boldsymbol{A}\right) & \gamma\left(\boldsymbol{R}_{\boldsymbol{t}}, \boldsymbol{B}\right) & \gamma\left(\boldsymbol{R}_{\boldsymbol{t}}, \boldsymbol{C}\right) \\
\gamma(\boldsymbol{\psi}, \boldsymbol{A}) & \gamma(\boldsymbol{\psi}, \boldsymbol{B}) & \gamma(\boldsymbol{\psi}, \boldsymbol{C})
\end{array}\right] \\
& =\left[\begin{array}{lll}
0.6534 & 0.6921 & 0.6531 \\
0.7217 & 0.7682 & 0.7166 \\
0.9052 & 0.8155 & 0.9008
\end{array}\right]
\end{aligned}
$$

By comparing Row 1, Row 2 and Row 3, some conclusion can be drawn from this matrix. In the first row, $\gamma(\mathrm{Ra}, \mathrm{B})$ $>\gamma(\mathrm{Ra}, \mathrm{A})>\gamma(\mathrm{Ra}, \mathrm{C})$, it means that the order of importance for the controllable factors to the $\mathrm{Ra}$, in sequence, is the factor B, A, and C. From the second row, $\gamma(\mathrm{Rt}, \mathrm{B})>\gamma(\mathrm{Rt}, \mathrm{A})$ $>\gamma(\mathrm{Rt}, \mathrm{C})$, the order of importance for the controllable factors to the Rt, in sequence, is the factor B, A, and C. Similarly, based on the third row, $\gamma(\psi, \mathrm{A})>\gamma(\psi, \mathrm{C})>\gamma(\psi, \mathrm{B})$, the order of importance for the controllable factors to the $\psi$, in sequence, is the factor $\mathrm{A}, \mathrm{C}$, and $\mathrm{B}$. Additionally, in the matrix, it also shows that the sequences for the $\gamma(\mathrm{Ra})$ and the $\gamma(\mathrm{Rt})$ are similar.

The most influential factors that affect the output variables are determined by identifying the maximum values in each row. Hence, base on the maximum values in the matrix of the grey relational $(\gamma(R a, B), \gamma(R t, B), \gamma(\psi, A))=(0.6921$, $0.7682,0.9052)$, it can be found that the factor A, cutting speed, has the most influence on the $\psi$ with $\gamma$ value of 0.9052. The factor $\mathrm{B}$, the feed rate, is the most influential factor to the $\mathrm{Ra}$ and the Rt with $\gamma$ values of 0.6921 and 0.7682 , respectively.

Additionally, Table $\mathbf{1 0}$ gives the results of the analysis of variance (ANOVA) for the $\mathrm{Ra}$, the $\mathrm{Rt}$, and the $\psi$ using the calculated values from the grey relational grade of Table 4 and the response table of Table 5. According to Table 10, the factor $\mathrm{B}$, the feed rate with $90.09 \%$ of contribution, is the most significant controlled parameters for the CNC boring operations; the cutting speed is with $1.31 \%$ contribution, and the depth of cutting with $0.79 \%$ of contribution if the minimization of the roughness average, roughness maximum and roundness are simultaneously considered.

\section{Confirmation Test}

After identifying the most influential parameters, the final phase is to verify the $\mathrm{Ra}, \mathrm{Rt}$, and the $\psi$ by conducting the confirmation experiments. The $\mathrm{A}_{2} \mathrm{~B}_{1} \mathrm{C}_{3}$ is an optimal parameter combination of the $\mathrm{CNC}$ boring process via the GRA. Therefore, the condition $\mathrm{A}_{2} \mathrm{~B}_{1} \mathrm{C}_{3}$ of the optimal parameter combination of the $\mathrm{CNC}$ boring process was treated as a confirmation test. If the optimal setting with a 
Table 7. The Calculated Grey Relational Coefficient and Grey Relational Grade for Experimental Factors to Experimental Result of the Ra

\begin{tabular}{|c|c|c|c|}
\hline & A & B & C \\
\hline \hline \multirow{7}{*}{$\begin{array}{c}\text { Grey Relational } \\
\text { Coefficient }\end{array}$} & 1.0000 & 1.0000 & 1.0000 \\
\cline { 2 - 4 } & 0.6386 & 0.7161 & 0.6564 \\
\cline { 2 - 4 } & 0.3518 & 0.3994 & 0.3626 \\
\cline { 2 - 4 } & 0.9533 & 0.9875 & 0.9113 \\
\cline { 2 - 4 } & 0.3333 & 0.6877 & 0.6159 \\
\cline { 2 - 4 } & 0.9594 & 0.9707 & 0.3340 \\
\cline { 2 - 4 } & 0.6478 & 0.6911 & 0.6529 \\
\cline { 2 - 4 } & 0.3661 & 0.4057 & 0.3567 \\
\hline \multirow{7}{*}{ Grey Relational Grade } & 0.6534 & 0.6921 & 0.6531 \\
\hline
\end{tabular}

Table 8. The Calculated Grey Relational Coefficient and Grey Relational Grade for Experimental Factors to Experimental Result of the Rt

\begin{tabular}{|c|c|c|c|}
\hline \multirow{7}{*}{$\begin{array}{c}\text { Grey Relational } \\
\text { Coefficient }\end{array}$} & 1.0000 & 1.0000 & 1.0000 \\
\cline { 2 - 4 } & 0.7243 & 0.8256 & 0.7472 \\
\cline { 2 - 4 } & 0.4767 & 0.5684 & 0.4967 \\
\cline { 2 - 4 } & 0.9697 & 0.9949 & 0.9263 \\
\cline { 2 - 4 } & 0.6272 & 0.6843 & 0.6132 \\
\cline { 2 - 4 } & 0.3593 & 0.4031 & 0.3601 \\
\cline { 2 - 4 } & 0.9236 & 0.8656 & 0.8985 \\
\cline { 2 - 4 } & 0.9154 & 0.9957 & 0.9256 \\
\cline { 2 - 4 } & 0.4995 & 0.5761 & 0.4820 \\
\hline Grey Relational Grade & 0.7217 & 0.7682 & 0.7166 \\
\hline
\end{tabular}

cutting speed of $85 \mathrm{~m} / \mathrm{min}, 0.05 \mathrm{~mm} / \mathrm{rev}$ of the feed rate, and a cut depth of $0.6 \mathrm{~mm}$ is used, the final workpiece gives the
Table 9. The Calculated Grey Relational Coefficient and Grey Relational Grade for Experimental Factors to Experimental Result of the $\psi$

\begin{tabular}{|c|c|c|c|}
\hline \multirow{7}{*}{$\begin{array}{c}\text { Grey Relational } \\
\text { Coefficient }\end{array}$} & 1.0000 & 1.0000 & $\mathbf{A}$ \\
\cline { 2 - 4 } & 0.9737 & 0.8359 & 0.9351 \\
\cline { 2 - 4 } & 0.9293 & 0.7068 & 0.8615 \\
\cline { 2 - 4 } & 0.8591 & 0.8868 & 0.8249 \\
\cline { 2 - 4 } & 0.8683 & 0.7784 & 0.8966 \\
\cline { 2 - 4 } & 0.8911 & 0.7019 & 0.8863 \\
\cline { 2 - 4 } & 0.8298 & 0.8830 & 0.8511 \\
\cline { 2 - 4 } & 0.8781 & 0.8093 & 0.8688 \\
\cline { 2 - 4 } & 0.9176 & 0.7375 & 0.9831 \\
\hline \multirow{7}{*}{ Grey Relational Grade } & 0.9052 & 0.8155 & 0.9008 \\
\hline
\end{tabular}

roughness average (i.e., $\mathrm{Ra}$ ) of $0.1368 \mu \mathrm{m}$, the roughness maximum (i.e., Rt) of $1.1250 \mu \mathrm{m}$, and the roundness (i.e., $\psi$ ) of $0.6428 \mu \mathrm{m}$.

\section{CONCLUSIONS}

The GRA based on an orthogonal array of the Taguchi method was a way of optimizing the $\mathrm{CNC}$ boring operations for aluminum alloy 6061T6. The analytical results are summarized as follows.

1. From the response table of the average grey relational grade, it is found that the largest value of the grey relational grade for the cutting speed of $85 \mathrm{~m} / \mathrm{min}$, the feed rate of $0.05 \mathrm{~mm} / \mathrm{rev}$, and the depth of cutting of $0.6 \mathrm{~mm}$. It is the recommended levels of the controllable parameters of the $\mathrm{CNC}$ boring operations as the minimization of the roughness average, roughness maximum and roundness are simultaneously considered.

2. The order of the importance for the controllable factors to the roughness average, in sequence, is the feed rate, the cutting speed, and the depth of cut. Similarly, the order to the roughness maximum, in sequence, is the feed rate, the cutting speed, and the depth of cut. Additionally, the order to the roundness, in sequence, is the cutting speed, the depth of cut, and the feed rate.

Table 10. ANOVA Results for Ra, Rt, and $\psi$

\begin{tabular}{|c|c|c|c|c|c|c|c|c|c|}
\hline Factor & Level 1 & Level 2 & Level 3 & $\begin{array}{c}\text { Degree of } \\
\text { Freedom }\end{array}$ & $\begin{array}{c}\text { Sum of } \\
\text { Squares }\end{array}$ & $\begin{array}{c}\text { Mean } \\
\text { Square }\end{array}$ & F value & $\begin{array}{c}\text { Excepted Sum } \\
\text { of Square }\end{array}$ & $\begin{array}{c}\text { Contribution (\%) } \\
\text { A }\end{array}$ \\
\hline \hline B & 0.6000 & 0.6868 & 0.6626 & 2 & 0.0120 & 0.0060 & 1.671 & 0.005 & 1.31 \\
\hline C & 0.6118 & 0.6442 & 0.6934 & 2 & 0.0101 & 0.0051 & 1.403 & 0.003 & 0.332 \\
\hline Error & & & & 2 & 0.0072 & 0.0036 & & 0.029 & 7.81 \\
\hline Total & & & & 8 & 0.3690 & 0.0461 & & 0.369 & 100.00 \\
\hline
\end{tabular}


3. Through ANOVA, the percentage of contribution to the $\mathrm{CNC}$ boring process, in sequence, is the feed rate, the cutting speed, and the depth of cut. Hence, the feed rate is the most significant controlled factor for the $\mathrm{CNC}$ boring operation when the minimization of the roughness average, the roughness maximum and the roundness are simultaneously considered.

4. Via experimental runs of the $\mathrm{CNC}$ boring operation can be gained finishing processing for the roughness average, namely, the roughness average is about $0.13 \mu \mathrm{m}$ by CNC boring process for aluminum alloy $6061 \mathrm{~T} 6$.

\section{ACKNOWLEDGEMENTS}

The authors would like to thank the National Science Council of the Republic of China, for financially supporting this research (Contract No. NSC95-2622-E-159-001-CC3) and Ming Hsin University of Science and Technology (Contract No. MUST-97-ME-009).

\section{REFERENCES}

[1] J. L. Deng, "Introduction to Grey System Theory", J. Grey Syst., vol. 1, pp. 1-24, 1989.

[2] J. T. Huang and J. L. Lin, "Optimization of machining parameters setting of die-sinking EDM process based on the grey relational analysis with L18 orthogonal array", J. Technol., vol. 17, pp. 659-664, 2002.

[3] C. P. Fung, C. H. Huang and J. L. Doong, "The study on the optimization of injection molding process parameters with Gray Relational Analysis", J. Reinf. Plast. Comps., vol. 22, pp. 51-66, 2003.

[4] Y. K. Shen, H. W. Chien and Y. Lin, "Optimization of the micro-injection molding process using grey relational analysis and moldflow analysis", J. Reinf. Plast. Comps., vol. 23, pp. 1799-1814, 2004.
[5] C.L. Lin, "Use of the Taguchi method and grey relational analysis to optimize turning operations with multiple performance characteristics", Mater. Manuf. Process., vol. 19, no. 2, pp. 209-220, 2004.

[6] K. T. Chiang and F. P. Chang, "Optimization of the WEDM process of particle-reinforced material with multiple performance characteristics using grey relational analysis, J. Mater. Process. Technol., vol. 108, pp. 96-101, 2006.

[7] Y. K. Yang, J. R. Shie and C. H. Huang, "Optimization of dry machining parameters for high-purity graphite in end milling process”, Mater. Manuf. Process., vol. 21, no. 8, pp. 832-837, 2006.

[8] D. C. Chen and C. F. Chen, "Use of Taguchi method to study a robust design for the sectioned beams curvature during rolling", $J$. Mater. Process. Technol., vol. 190, pp. 130-137, 2007.

[9] C. P. Fung and P. C. Kang, "Multi-response optimization in friction properties of PBT composites using Taguchi method and principle component analysis", J. Mater. Process. Technol., vol. 170, pp. 602-610, 2005.

[10] S. H. Tang, V. J. Tan, S. M. Sapuan, S. Sulaiman, N. Ismail and R. Samin, "The use of Taguchi method in the design of plastic injection mould for reducing warpage", J. Mater. Process. Technol., vol. 182, pp. 418-426, 2007.

[11] P. Vijian and V. P. Arunachalam, "Optimization of squeeze cast parameters of LM6 aluminium alloy for surface roughness using Taguchi method", J. Mater. Process. Technol., vol. 180, pp. 161-166, 2006.

[12] L. J. Yang, "The effect of specimen thickness on the hardness of plasma surface hardened ASSAB 760 steel specimens", J. Mater. Process. Technol., vol. 185, pp. 113-119, 2007.

[13] J. Z. Zhang, J. C. Chen and E. D. Kirby, "Surface roughness optimization in a end-milling operation using the Taguchi design method", J. Mater. Process. Technol., vol. 184, pp. 233-239, 2007.

[14] H. S. Gau, C. Y. Hsieh and C. W. Liu, "Application of grey correlation method to evaluate potential groundwater recharge sites", Stoch. Environ. Res. Risk Assess., vol. 20, pp. 407-421, 2006.

[15] M. L. You, C. W. Wang and C. K. Yeh, "The development of completed grey relational analysis toolbox via matlab", J. Grey Syst., vol. 9, no .1, pp. 57-64, 2007.

[16] S. Kalpakjian and S. R. Schmid, Manufacturing engineering and technology, $5^{\text {th }}$ ed. Prentice Hall Inc., New Jersey, 2005.

(C) Lin et al.; Licensee Bentham Open.

This is an open access article licensed under the terms of the Creative Commons Attribution Non-Commercial License (http://creativecommons.org/ licenses/by-nc/3.0/) which permits unrestricted, non-commercial use, distribution and reproduction in any medium, provided the work is properly cited. 